\title{
Isolation and identification of Lactobacillus species from the vagina and their antimicrobial properties
}

\author{
Mansour Amin ${ }^{1,2}$, Hamed Goodarzi ${ }^{1 \star}$, Ziba Orang $^{1}$, Sakineh Farsi ${ }^{1}$ and Maasomeh Jorfi ${ }^{1}$ \\ ${ }^{1}$ Department of Microbiology, School of Medicine, Research Center, Ahvaz Jundishapur University of Medical Sciences, \\ Ahvaz, Iran. \\ ${ }^{2}$ Medicinal Plants and Natural Products Research Center, Ahvaz Jundishapur University of Medical Sciences, Ahvaz,
} Iran.

Accepted 23 August, 2011

\begin{abstract}
The microbial resident in the vagina is a heterogeneous flora containing bacteria. This microbial flora plays an important role in regular vagina function and support host defense from attack by pathogens. In this study Lactobacilli spp. isolated from healthy women and their antimicrobial activity was evaluated. One hundred and three healthy women referred to women clinics in Ahvaz-Iran were subjected for this study. A vaginal swab of each one inoculated in MRS broth media. After $24 \mathrm{~h}$ incubation the specimens were subcultured on MRS agar media. The Gram positive bacilli where isolated for more identification by using polymerase chain reaction (PCR) with genus and speciesspecific primers. The antimicrobial activity of confirmed lactobacilli where tested against Candida albicans and Staphylococcus aureus. Fifty-one samples out of 103 were positive for Lactobacillus genus primers. Twenty-four isolates were Lactobacillus acidophilus and two species were identified as Lactobacillus plantarum and 2 as Lactobacillus casei. Twenty-three other isolates were just positive by genus primer. Twenty strains of $L$. acidophilus and one strain of $L$. plantarum, showed antimicrobial activity against $S$. aureus and $C$. albicans. The objectives of this study showed that less than $50 \%$ of healthy ladies in Ahvaz city- Iran can be supported from vaginal pathogens by lactobacilli probiotics but others are in risk of attack by harmful microbes.
\end{abstract}

Key word: Lactobacillus, vagina pathogens, antimicrobial.

\section{INTRODUCTION}

Recently, an increasing interest has developed in microbiota that promotes a woman's health. In particular, Lactobacillus species, that are commonly present in the human vagina, have received considerable attention due to their protective and probiotic properties (Andreu, 2004). Lactobacilli produce acids, hydrogen peroxide $\left(\mathrm{H}_{2} \mathrm{O}_{2}\right)$, bacteriocins and biosurfactants and thus confer protection of the host (Reid and Bruce, 2003). The vagina of healthy women is a typical balanced ecosystem in which lactobacilli consist of more than $95 \%$ of flora. The

*Corresponding author. E-mail: Goodarzi200055@yahoo.com. Tel: +989177058977. Fax: +986113332036. predominant lactobacilli can be isolated from vagina with a recovery rate of 50 to $80 \%$ and a microbial load of about $8 \times 10^{7} \mathrm{CFU} / \mathrm{ml}$. The lactobacilli-dominant vaginal flora have been proved to be of utmost importance for preventing various urogenital infections (UI), including recurrent urinary tract infections (UTI) and bacterial vaginosis (BV), a common disease with an infection rate of $27.86 \%$ in Chinese women, characterized by decreased lactobacilli and overgrowth of other microorganism (Xu et al., 2008). Lactobacilli are acidotolerant, and the most frequently described mechanism for the control of growth of other populations by lactobacilli has been through the production of lactic acid from glycogen in vagina of healthy women. Among the properties of most vaginal strains of lactobacilli is their ability to 
Table 1. Primers that used for this study (Massi et al., 2004).

\begin{tabular}{lllc}
\hline Name & & Primer & bp \\
\hline Lactobacillus genus & Forward & 5-GGGTTCCCCATTCGGA-3 & 560-640 \\
& Reverse & 5-GAATCGCTAGTAAATTCG-3 & \\
L. acidophilus & Forward & 3-CCTTTCTAAGGAAGCGAAGGAT-5 & 199 \\
& Reverse & 3-AATTCTCTTCTCGGTCGCTCTA-5 & \\
L. casei & Forward & 5-AAGCACCCTAACGGGTGCGACT-3 & 118 \\
& Reverse & 5-GCGATGCGAATTCTTTTTC-3 & \\
L. plantarum & Forward & 5-TCGGGATTACCAAACATCAC-3 & 319 \\
& Reverse & 5-CCGTTTATGCGGAACACCTA-3 & \\
\hline
\end{tabular}

to release $\mathrm{H}_{2} \mathrm{O}_{2}$ in appreciable amounts in vitro. The hydrogen peroxide formed by $\mathrm{H}_{2} \mathrm{O}_{2}$ generating bacteria can be auto inhibitory or be toxic to adjacent bacteria, fungi, viruses (Klebanoff et al., 1991), particularly in the presence of peroxidase and halide. Bacteriocins are defined as proteinaceous, bacterial substances synthesized by bacteria, which usually have a Review Boris and Barbés narrow spectrum of activity, inhibiting strains of the same or closely related species. A bacteriocin-like substance is a term applied to antagonistic substances, which are incompletely defined or do not fit the typical criteria of bacteriocins. They tend to have a broader spectrum of activity than bacteriocins. A great number of these substances have been reported to be produced by lactobacilli, inhibiting a wide range of both Gram-positive and -negative bacteria as well as fungi. McGroarty and Reid described one such substance which showed activity in vitro against uropathogenic Escherichia. coli and Enterococcus species (McGroarty and Reid, 1998), but the role of these substances in vivo remains to be elucidated. Other mechanisms proposed for their microbial antagonism are competition for nutrients (McFarland, 2000; Reid and Burton, 2002), adhesion inhibition of pathogens to surfaces (Reid and Burton, 2002; Vesterlund et al., 2006), and stimulation of the immune system (Gill et al., 2001; Adel-Patient et al., 2005) then when the vaginal lactobacilli are diminished or absent, other microorganisms may grow excessively, causing disorders including bacterial vaginosis (BV), yeast vaginitis and sexually transmitted diseases (STD) (Burton et al., 2003). The main goal was to define their spectrum of antagonistic activity and to select the uropathogens-inhibiting strains with putative ability to protect the vagina. We attempted to isolate lactobacilli strains from healthy woman vaginal ecosystem that commonly referred to clinics for recheck. These strains were identified and initially tested for their probiotic properties. The inhibitory effect of these strains on both Gram-positive and Gram-negative pathogenic bacteria and fungi was further investigated.

\section{MATERIALS AND METHODS}

\section{Isolation and identification of lactobacilli from vaginal specimens}

Vaginal specimens were obtained from 103 women between the ages of 25 and 50 years with healthy vaginal ecosystems that referred to women clinics in Ahvaz- Iran. Lateral vaginal walls were swabbed with sterile cotton-tipped applicators. Lactobacilli were isolated by inoculating on de Man-Rogosa Sharpe agar (MRS agar, Difco, Detroit, USA) with $0.3 \%$ bile oxgall (Sigma, Lousiana, USA) and $0.2 \%$ bromocresol purple (Merck, Darmstadt, Germany ), incubated anaerobically at $37^{\circ} \mathrm{C}$ for $48 \mathrm{~h}$ using an anaerobic jar containing anaerobic pak. Identification of Lactobacillus species was performed by phenotypic criteria. All isolates were initially tested for colony morphology, Gram reaction, catalase activity, motility test, and gas production from glucose (Voravuthikuncha et al., 2006). Polymerase chain reaction (PCR) analyses are then performed on the extracted DNA from Stock cultures were stored at $-70^{\circ} \mathrm{C}$ in skim milk. 1-2 loop of the confirmed bacteria with phenotypically analysis grown on MRS agar, were resolved in TE (Trace EDTA) buffer and boiled at $100^{\circ} \mathrm{C}$ for $15 \mathrm{~min}$. Extracted DNA was selected for PCR analyses by using genus and speciesspecific primers (Table 1).

The PCR conditions were initial denaturation of $94^{\circ} \mathrm{Cfor} 5 \mathrm{~min}$ followed by 30 cycle of denaturation of $94^{\circ} \mathrm{C}$ for $30 \mathrm{~s}$, annealing of $52^{\circ} \mathrm{C}$ for $30 \mathrm{~s}$ for cas-ITS genus specific primers; $45^{\circ} \mathrm{Cfor} 45 \mathrm{~s}$ for Lactobacillus plantarum; $40^{\circ} \mathrm{C}$ for 40 s for Lactobacillus casei and final extention at $72^{\circ} \mathrm{C}$ for 10 min using a termocycler (eppendorf). The PCR products were analyzed on $1 \%$ agaros gel. The confirmed species by PCR were tested for antimicrobial properties.

\section{Determination of antimicrobial products}

Antimicrobial compound was isolated using ethyl acetate solvent from $L$. acidophilus and L. plantarum. After 5 days incubation, the MRS broth media containing bacteria was mixed with ethyl acetate and agitated with a magnetic stirrer for two days. Then the media was allowed to settle for $30 \mathrm{~min}$. Following settlement, the solution 


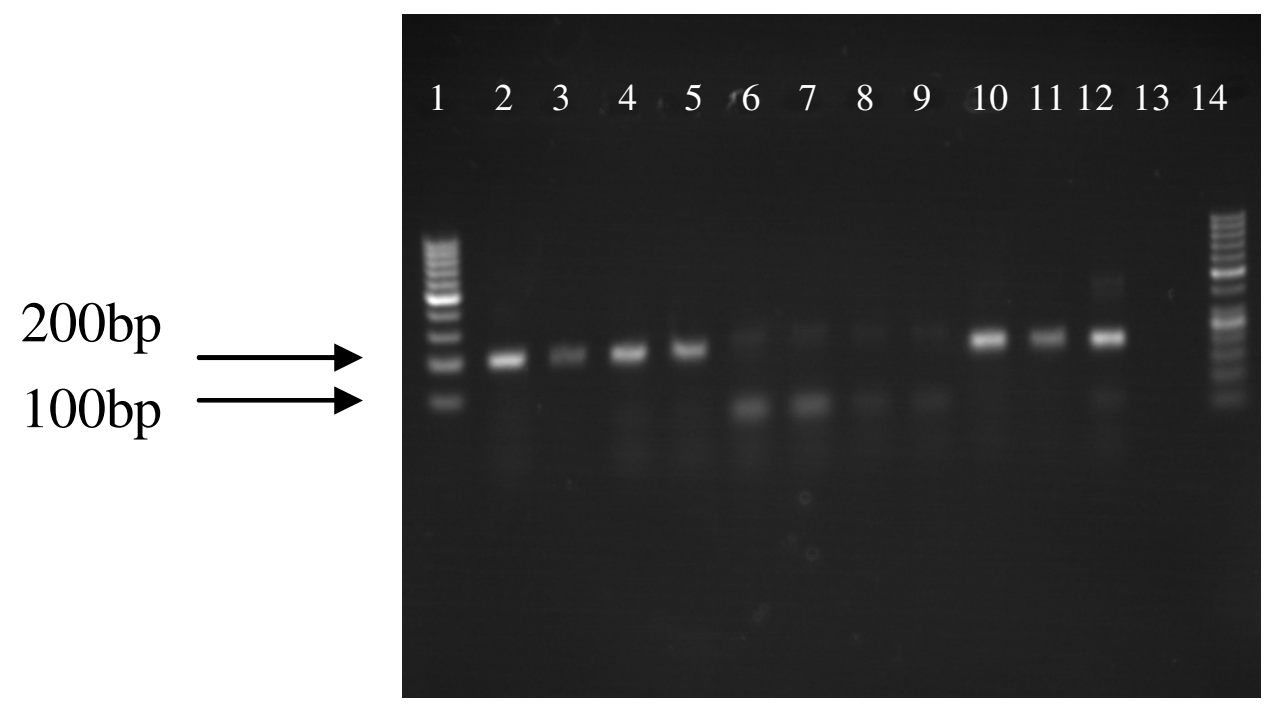

Figure 1. Agarose gel of PCR products amplified by species-specific primers of $L$. plantarum and $L$. acidophilus; 1 :marker100bp- 2,3,4,5,10,11,12 L .acidophilus; 14 : marker 50 bp.

was separated into two phases, which the supernatant was comprised of the extracted antimicrobial compound (Settanni et al., 2005). The color of ethyl acetate was turned yellow after agitation. The supernatant then was dried at $45^{\circ} \mathrm{C}$. The yield of dried antimicrobial compound was $20 \mathrm{mg}$. The activity of antimicrobial agent was tested against pathogen microorganisms after adjustment of $\mathrm{pH}$ at 7 using $\mathrm{NaOH} 5 \mathrm{~N}$. The minimal inhibitory concentration (MIC) of this antimicrobial substance determined using modified $\mathrm{E}$. test (Amin et al., 2009). The target bacteria were Staphylococcus aureus (ATCC1189) and Candida albicans (ATCC 5027). The tests were performed 3 times.

\section{RESULTS}

Fifty- one samples out of 103 were positive for lactobacillus genus primers. Twenty - four isolates were $L$. acidophilus and 2 species were identified as $L$. plantarum and 2 spices as $L$. casei. Twenty three other isolates were just positive by genus primer (Figure 1). The antimicrobial compounds showed potent inhibitory activity against all tested microbes. The MICs of antimicrobial compound extracted from $L$. acidophilus were 4 and $1 \mu \mathrm{g} / \mathrm{ml}$ for $S$. aureus and $C$. albicans respectively (Figures 2 and 3 ), while L. plantarum and L. casei did not show any antimicrobial effect.

\section{DISCUSSION}

It has been well-documented that lactobacilli can act competitively to exclude pathogens, inhibiting their colonization and subsequently preventing infection. We made an attempt to select a good probiotic strain that could be used as therapeutic medicine. A wide range of pathogenic bacteria responsible for urinary tract infections were used in this study. The importance of vaginal Lactobacillus as a barrier to infections is of considerable interest. The experiments that demonstrate their protective role in a woman's health would benefit from the development of simple methods, allowing their detection and identification. In the present study, different in vitro methods were applied to characterize the antagonistic properties of Lactobacillus.

The results of this study showed that $49.5 \%$ of healthy women in Ahvaz- Iran have possibility of colonizing the Lactobacillus in their vagina. According to benefits of these bacteria for the protection of vagina, the quantity of this probiotic should be increased in the vagina of ladies. $70 \%$ of women that were positive for colonizing lactobacilli take place in range between 20 to 40 years old. 42 out of 103 under study women had vaginal infection at lease once in their life and $82 \%$ out of them were negative for Lactobacillus. To investigate the indigenous lactobacilli from the vagina, Xu et al. (2008) studied on one hundred and three lactobacilli strains were isolated from 60 samples of vaginal secretion from healthy pregnant women. Among them, 78 strains could produce hydrogen peroxide, in which $68,80,80$ and $88 \%$ had antagonistic effects against Candida albicans, Staphylococcus aureus, Escherichia coli, and Pseudomonas aeruginosa, respectively.

The lactobacillus strains were then further studied by Voravuthikuncha et al. (2006) for their probiotic properties. All of these strains were able to produce $\mathrm{H}_{2} \mathrm{O}_{2}$. All strains grew well at $\mathrm{pH} 5$, however, only strains $L$ 01A, L 01B, L 19A, and L 22 demonstrated growth at $\mathrm{pH}$. The results of their ability to utilize protein, starch, 


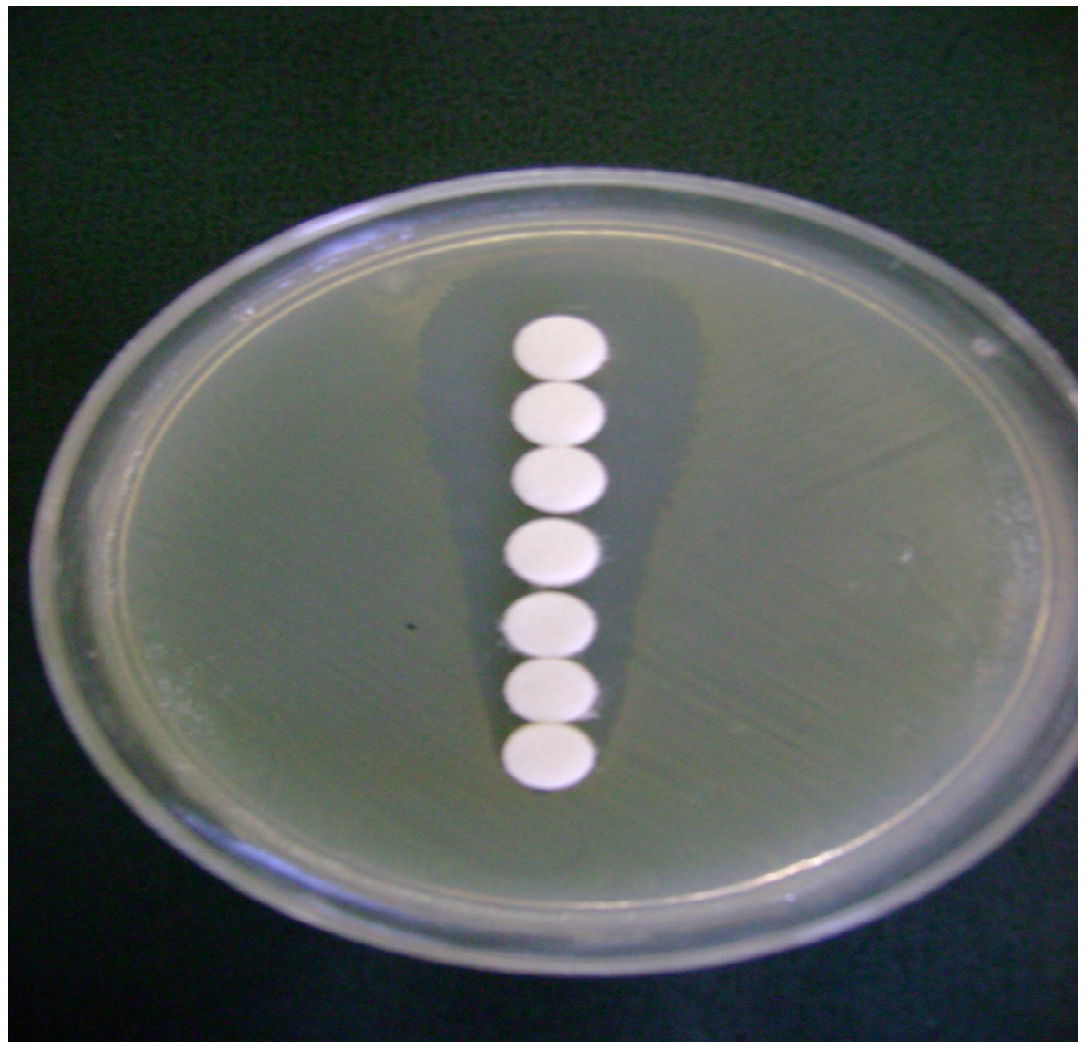

Figure 2. E test representing MIC of antimicrobial compound obtained from $L$. acidophilus against $S$. aureus.

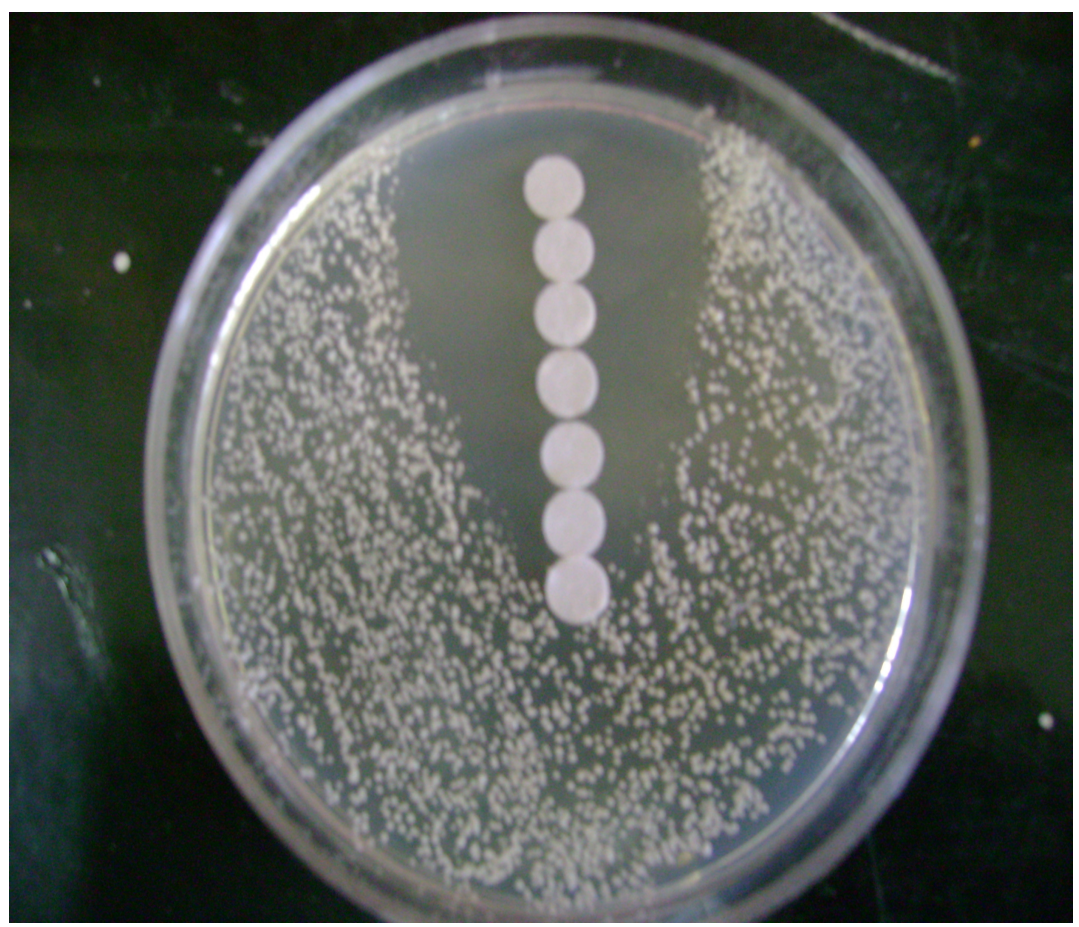

Figure 3. E test representing MIC of antimicrobial compound obtained from $L$. acidophilus against $C$. albicans. 
and lipid are presented in. None of these strains were able to utilize starch and lipid. Six strains (L12A, L 12B, L $19 A, L 19 B, L 20$ and L 22) were shown to hydrolyse protein.

\section{Conclusion}

The objectives of this study showed that less than $50 \%$ of healthy ladies in Ahvaz city- Iran can be supported from vaginal pathogens by lactobacilli probiotics but others are in risk of attack by harmful microbes. The food containing probiotis may be colonized by the Lactobacillus and Bifidobacterium species in the vagina through oral- fecalvaginal track.

\section{REFERENCES}

Adel-Patient K, Ah-Leung S, Creminon C, Nouaille S, Chatel JM, Langella $P$ (2005). Oral administration of recombinant Lactococcus lactis expressing bovine beta-lactoglobulin partially prevents mice from sensitization.Clin. Exp. Allergy., 35: 539-46

Amin $M$, Jorfi $M$, Khosravi AD, Samarbafzadeh AR, Farajzadeh SA (2009). Isolation and Identification of Lactobacillus casei and Lactobacillus plantarum from Plants by PCR and Detection of their Antibacterial Activity. J. Biol. Sci., 9(8): 810-814

Andreu A (2004). Lactobacillus as a probiotic for preventing urogenital infections. Rev. Med. Microbiol., 15: 1-6.

Burton JP, Cadieux PA, Reid G (2003). Improved understanding of the bacterial vaginal microbiota of women before and after probioticinstillation. Appl. Environ. Microbiol., 69: 97-101.
Gill HS, Rutherfurd KJ, Cross ML, Gopal PK (2001). Enhancement of immunity in the elderly by dietary supplementation with the probiotic Bifidobacterium lactis HN019. Am. J. Clin. Nutr., 74: 833-839

Klebanoff SJ, Coombs RW (1991). Viricidal effect of Lactobacillus. acidophilus on human immunodeficiency virus type 1: possible role in heterosexual transmission, J. Exp. Med., 174: 289-292.

Massi M, Vitali B, Federici F, Matteuzzi D, Brigidi P (2004). Identification method based on PCR combined with automated ribotyping for tracking probiotic Lactobacillus strains colonizing the human gut and vagina. J. Appl. Microbiol., 96: 777-786.

McFarland LV (2000). Normal flora: diversity and functions. Microb. Ecol. Health Dis., 12: 193-207.

McGroarty JA, Reid G (1988). Inhibition of enterococci by Lactobacillus species in vitro, Microb. Ecol. Health Dis., 1: 215-219.

Reid G, Bruce AW (2003). Urogenital infections in women: can probiotics help? Postgrad Med. J., 79: 428-432.

Reid G, Burton J (2002). Use of Lactobacillus to prevent infection by pathogenic bacteria. Microbes Infect., 4: 319-324.

Settanni L, Sinderen DvR J, Corsetti A (2005). Rapid Differentiation and In Situ Detection of 16 Sourdough Lactobacillus species by Multiplex PCR. Appl. Environ. Microbiol., 71: 3049-3059.

Vesterlund S, Karp M, Salminen S, Ouwehand AC (2006). Staphylococcus aureus adheres to human intestinal mucus but can be displaced by certain lactic acid bacteria. Microbiology, 152: 18191826.

Voravuthikuncha SP, Bilaso S, Supamala O (2006). Antagonistic activity against pathogenic bacteriaby human vaginal lactobacilli. Anaerobe, 12: $221-226$

Xu HY, Tian WH, Wan CX, Jia LJ, Wang LY (2008). Antagonistic Potential against Pathogenic Microorganisms and Hydrogen Peroxide Production of Indigenous Lactobacilli Isolated from Vagina of Chinese Pregnant Women. Biomed. Environ. Sci., 21: 365-371 